Research Article

\title{
Preparation and Characterization of Spherical Submicron CL-20 by Siphon Spray Refinement
}

\author{
Jiangtao Xing $\mathbb{D}$, ${ }^{1}$ Weili Wang $\left(\mathbb{D},{ }^{1}\right.$ Wenzheng Xu $\left(\mathbb{D},{ }^{2}\right.$ Tianle Yao $\mathbb{D},{ }^{1}$ Jun Dong, \\ and Run Miao ${ }^{1}$ \\ ${ }^{1}$ College of Ordnance Engineering, Naval University of Engineering, Wuhan 430000, China \\ ${ }^{2}$ School of Environment and Safety Engineering, Shanxi Engineering Technology Research Center for Ultrafine Powder, \\ North University of China, Taiyuan 030051, China
}

Correspondence should be addressed to Weili Wang; w.l.wang@tom.com

Received 8 December 2019; Accepted 29 January 2020; Published 2 March 2020

Academic Editor: Laura Martinez Maestro

Copyright () 2020 Jiangtao Xing et al. This is an open access article distributed under the Creative Commons Attribution License, which permits unrestricted use, distribution, and reproduction in any medium, provided the original work is properly cited.

\begin{abstract}
In order to improve the safety of hexanitrohexaazaisowurtzitane (CL-20), submicron CL-20 particles were prepared by a siphon ultrasonic-assisted spray refining experimental device. The samples were characterized by scanning electron microscopy (SEM), X-ray diffraction (XRD), and differential scanning calorimetry (DSC), and the impact sensitivity of the samples was tested. The results show that the particle size of siphon-refined CL-20 is about $800 \mathrm{~nm} \sim 1 \mu \mathrm{m}$, which is more smooth, mellow, and dense than that of CL-20 prepared by a traditional pressure-refined method. The peak diffraction angle of pressure- and siphon-refined CL-20 is basically the same as that of raw CL-20, and their crystal forms are $\varepsilon$ type. The peak strength of pressure- and siphon-refined CL-20 decreased obviously. The apparent activation energy of pressure-refined CL-20 and siphon-refined CL-20 is $13.3 \mathrm{~kJ} / \mathrm{mol}$ and $11.95 \mathrm{~kJ} / \mathrm{mol}$ higher than that of raw CL-20, respectively. The thermal stability of CL-20 is improved. The activation enthalpy $\left(\Delta H^{\#}\right)$ is significantly higher than that of raw CL-20, and the characteristic drop is $70.4 \%$ and $82.7 \%$ higher than that of raw CL-20. The impact sensitivity of siphon-refined CL-20 is lower than that of pressure-refined CL-20, so the safety performance of an explosive is improved obviously.
\end{abstract}

\section{Introduction}

With the increasing military demand, high-energy explosives have also developed rapidly. The ammonium nitrate explosive is one of the typical explosives. Hexanitrohexaazaisowurtzitane (HNIW, CL-20), as one of the caged ammonium nitrate explosives, is favored by people. The molecular structure of CL-20 $\left(\mathrm{C}_{6} \mathrm{H}_{6} \mathrm{O}_{12} \mathrm{~N}_{12}\right)$ is shown in Figure 1. It is the most promising high-energy explosive to replace HMX in the synthesis of high-energy density materials. However, due to its high mechanical sensitivity and multifaceted crystal, it cannot meet the needs of explosive safety performance in the battlefield environment, so it needs to be refined to obtain highquality crystal to meet the requirements of explosive safety performance. In general, the common method to reduce the sensitivity of CL-20 crystal is refining treatment [1]. The particles prepared by the refining method have increased density, decreased mechanical sensitivity, disappeared sharp edges and corners, and elliptical particles. In addition, the physical characteristics of the refined CL-20 crystal, such as particle size, morphology, crystal type, purity, internal and external defects, and the microstructure of the crystal gap, also have a great impact on the sensitivity of CL-20.

The mechanical sensitivity of CL-20 explosives is reduced by means of refinement. The main methods commonly used include mechanical milling [2-4], chemical recrystallization $[5,6]$, spray drying $[7,8]$, and supercritical fluid recrystallization [9-11]. Wang et al. [12] used a gas-phase antisolvent method (GAS) prepared nano-HNIW. The size of HNIW nanoparticles was $120 \mathrm{~nm}-300 \mathrm{~nm}$, but the crystal type changed from $\varepsilon$ type to $\alpha$ type during recrystallization. Bayat and Zeynali $[13,14]$ used the microemulsion method to prepare nanoparticles of CL-20 via oil in water $(\mathrm{O} / \mathrm{W})$ microemulsions. The optimized formulation contains water 


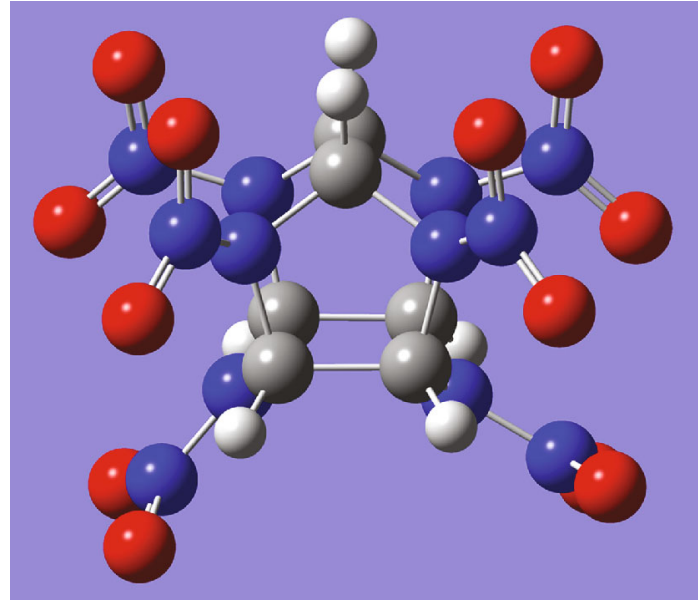

Figure 1: Molecular structure of CL-20.

$45 \%$, n-butyl acetate $20.5 \%$, sodium dodecyl sulfate (SDS, as anionic surfactant) $6.5 \%$, and 2-propanol (as cosurfactant) $26.5 \%$. Nanoparticles of CL-20 are spherical with an average diameter of $25 \mathrm{~nm}$. Another method is to spray CL-20 solution into nonsolvent (isooctane) with ethyl acetate as solvent and prepare nano-CL-20 by precipitation crystallization. The results show that CL-20 nanoparticles are spherical or ellipsoidal with an average particle size of $95 \mathrm{~nm}$. Because the particle diameter is small, the surface energy is high, and it is easy to agglomerate. Compared with CL-20 of the micron scale, CL20 of the nanometer scale has lower impact sensitivity. Zhang et al. [15] prepared spherical ultrafine CL-20 particles by a physical grinding method; introduced the working principle of a grinding refining device; analyzed the influence of grinding ball density and grinding time on the average particle size, particle size distribution, and sphericity of ultrafine CL-20; and tested the performance of spherical ultrafine CL-20. Results show that the superfine CL-20 particles obtained with low-density grinding balls are spherical, its mechanical sensitivity is significantly reduced, its thermal stability is better than raw CL-20, and the polymorph remains $\varepsilon$ type. Jia and Wang $[16,17]$ used a spray drying-assisted self-assembly (SDAS) technology to prepare submicron CL-20. The impact sensitivity of CL-20 refined by SDAS is $31.1 \mathrm{~m}$, and the probability of friction explosion is reduced to $80 \%$. However, it can be found that there are defects in the refined CL-20 crystal particles by SEM analysis. At the same time, submicron CL-20 particles were obtained by green mechanical demulsification, but agglomeration still existed. Pang et al. [18] prepared ultrafine spherical CL-20 particles by means of a compressed air spray device. Although the spheroidization of the prepared particles is higher and the characteristic drop height is increased from $17.8 \mathrm{~cm}$ to $33.9 \mathrm{~cm}$, the refined CL-20 crystal is $\beta$ type.

In this study, the principle of siphon air atomization was compared with the traditional atomization method to prepare fine CL-20 particles. A negative pressure (-0.03 MPa $-0.05 \mathrm{MPa})$ is generated at the liquid inlet inside the spray chamber. Under the action of negative pressure, the solution is inhaled into the spray chamber, and compressed air cuts the solution violently, thus realizing the atomization of the solution. The larger the air velocity is, the stronger the cutting effect is and the better the atomization effect is. So the effect of siphon atomization is better than that of traditional pressure atomization. A siphon ultrasonic-assisted spray refining experimental device was made by the siphon principle. Spherical submicron $\varepsilon$-CL-20 was prepared, and properties were tested and studied. This paper can provide reference for studying the safety of CL-20 explosives.

\section{Experimental Parts}

2.1. Materials. Raw CL-20 is produced in Liaoning Qingyang Chemical Industry Company. Ethyl acetate is produced in the Tianjin Beichen Fangzheng Reagent Factory. Heptane is produced in Tianjin Guangfu Fine Chemical Research Institute.

2.2. Pressure Ultrasonic-Assisted Spray Refining Experimental Device. The pressure-type ultrasonic-assisted spray refinement experimental device uses a conical pressure-type two fluid atomization form. On both sides of the nozzle are the liquid inlet and the air inlet. When entering the nozzle, the solution will produce a certain flow rate under the action of the air pump pressure. At the same time, at one end of the air inlet of the nozzle, under the action of another air pump, the gas will also have a certain speed. The solution and the gas will meet at the nozzle. Under the action of the pressure, the solution and the gas will rub against each other, so that the solution will quickly form ultrafine droplets. The diameter of the nozzle is $0.3 \mathrm{~mm}$. When the small droplets formed by the spray of solution from the nozzle contact with the nonsolvent, the small droplets are easy to form a local supersaturated state with the nonsolvent at the contact surface. The larger the supersaturated state gradient, the easier the nucleation.

The grains agglomerate with each other to form powder particles. With more and more fine droplets contacting with nonsolvent, a large number of crystals are separated out, thus realizing fine recrystallization of solute. The experimental device is shown in Figure 2.

\subsection{Siphon Ultrasonic-Assisted Spray Refining Experimental} Device. The siphon-type ultrasonic-assisted spray refinement device adopts a conical siphon dual fluid atomization. The special internal structure design of the conical siphon atomizer can make the liquid and the gas mix evenly and produce the tiny size droplets. Usually, the method of increasing the inlet pressure or reducing the inlet pressure is used to make the atomized droplets smaller.

Siphon atomization can produce a desired spray droplet without changing the air pressure and liquid pressure by adjusting the liquid flow rate, so it has strong adaptability. The principle of the siphon atomizing nozzle is that the air enters into the annular cavity at a certain flow rate after being compressed, and a negative pressure $(-0.03 \mathrm{MPa} \sim-0.05 \mathrm{MPa})$ is generated inside it. Under the action of negative pressure, the solution is sucked into the spray chamber to cut the solution with compressed air, thus realizing the atomization of the solution. When the air flow rate is larger, the cutting effect is stronger and the atomization effect is better, so the atomization effect of the siphon type is better than that of 


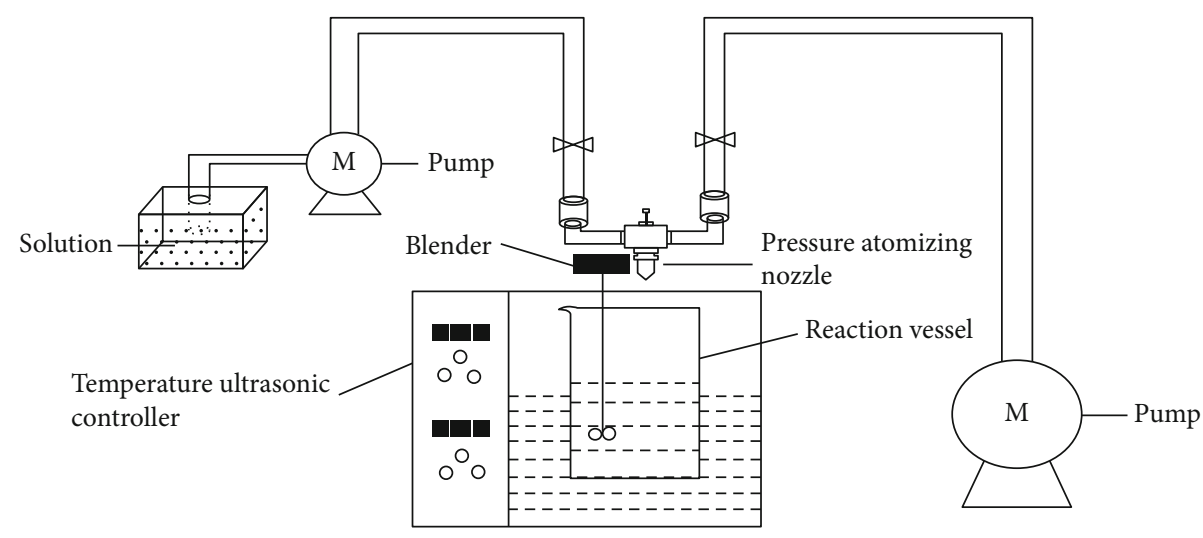

FIGURE 2: Pressure ultrasonic-assisted spray refining experimental device.

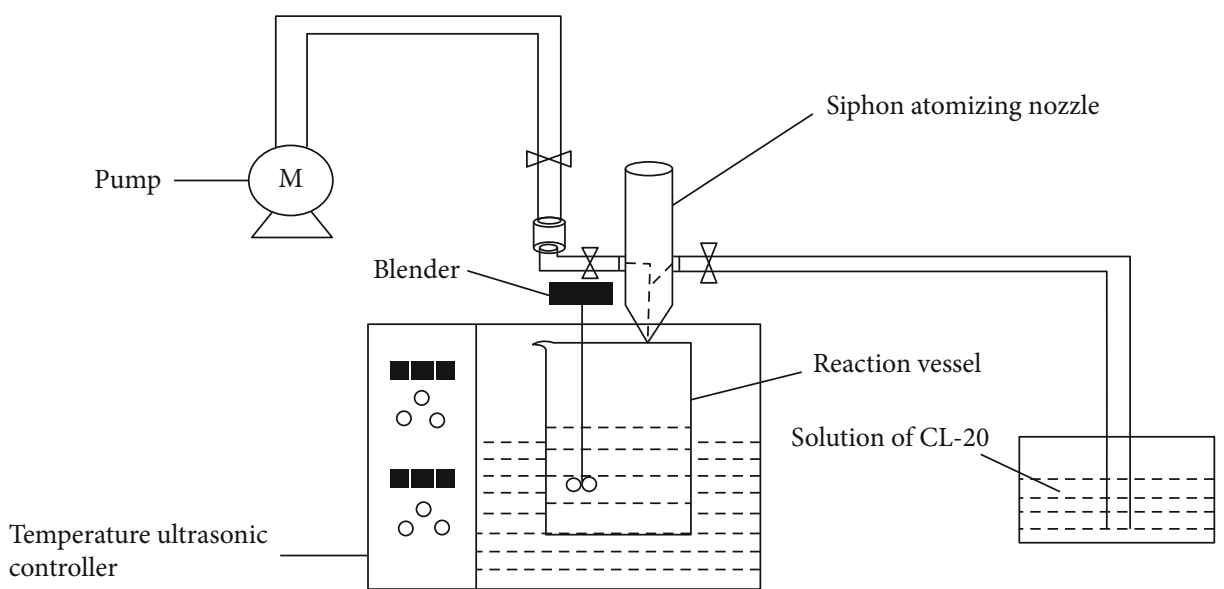

FIGURE 3: Siphon ultrasonic-assisted spray refining experimental device.

the pressure type. Because siphon spray is absorbed by negative pressure and the pressure is small, the inlet port does not need to be equipped with a booster pump. The experimental device is shown in Figure 3.

2.4. Preparation of Ultrafine CL-20. At room temperature and atmospheric pressure, $10 \mathrm{~g}$ CL-20 was added into a beaker containing $50 \mathrm{ml}$ ethyl acetate and then stirred until completely dissolved. Two sets of the self-made ultrasonicassisted spray refining device were adopted, respectively. Pour CL-20 solution into the tube at the inlet end of the atomizing nozzle, and turn on the high-pressure pump. Under the action of pressure, the CL-20 solution is sprayed into $250 \mathrm{ml} \mathrm{n}$-heptane at the speed of $1 \mathrm{ml} / \mathrm{min}$ through the atomizing nozzle to form small droplets.

In this process, the stirring speed is $300 \mathrm{r} / \mathrm{min} \sim 350 \mathrm{r} / \mathrm{min}$. Because of the heat generated in the ultrasonic process, the temperature of nonsolvent will increase, so the temperature should be adjusted in the experimental process, and the temperature should be controlled below $60^{\circ} \mathrm{C}$. The white suspension was obtained by ultrasonic stirring for 30 minutes, and then, the white suspension was washed, filtered, and vacuum freeze-dried to obtain spherical CL-20 fine particles.
2.5. Characterization. A field emission scanning electron microscope (FESEM, S4700 Hitachi, Ltd., Japan) was used to characterize the morphology, size, and microstructure of particles. X-ray diffraction (XRD) patterns were obtained using a DX-2700 (Dandong Haoyuan Corporation, Liaoning, China) X-ray diffractometer with $\mathrm{Cu}-\mathrm{K} \alpha(40 \mathrm{kV}, 30 \mathrm{~mA})$ radiation at $\lambda=1.5418 \AA$. All samples were scanned from $5^{\circ}$ to $50^{\circ}$ with steps 0.03 and $6 \mathrm{~s}$ counting time. The thermal properties were characterized by a Setaram DSC-131 (Setaram, Hillsborough Township, NJ, USA). The DSC conditions were as follows: sample mass: $0.7 \mathrm{mg}$; heating rate: $5 \mathrm{~K} / \mathrm{min}, 10 \mathrm{~K} / \mathrm{min}$, and $20 \mathrm{~K} / \mathrm{min}$; and nitrogen atmosphere (flow rate: $20 \mathrm{ml} / \mathrm{min}$ ). The impact sensitivity of each test sample was characterized by the drop height of 50\% explosion probability $\left(H_{50}\right)$. The experimental conditions were as follows: drop weight is $2.5 \mathrm{~kg}$, sample mass is $35 \pm 1 \mathrm{Mg}$, test temperature is $10 \sim 35^{\circ} \mathrm{C}$, relative humidity $\leq 80 \%$, and each sample was tested 25 times to obtain $H_{50}$.

\section{Results and Discussion}

3.1. Morphology Analysis. The collected two kinds of refined CL-20 particles and raw CL-20 were tested by field emission 


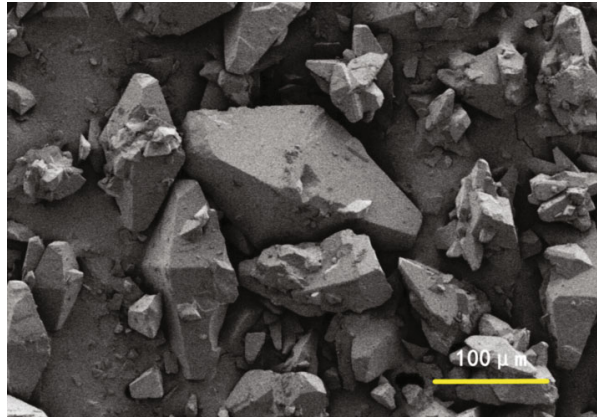

(a) Raw CL-20

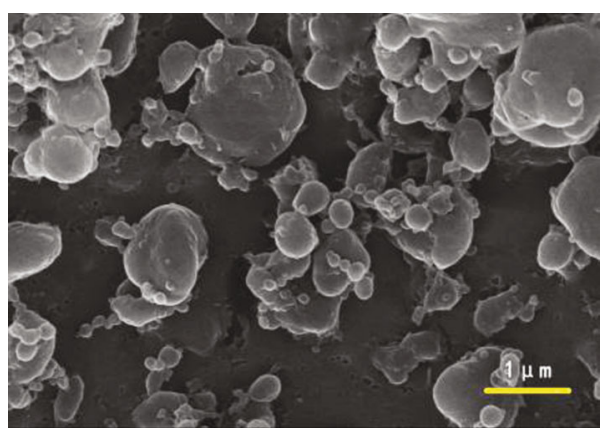

(b) Pressure-refined CL-20

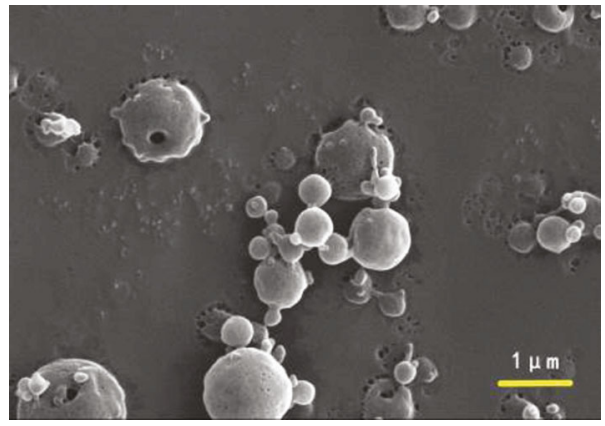

(c) Siphon-refined CL-20

FIgURE 4: SEM images of different CL-20 samples.

scanning electron microscopy (FESEM, HITACHI S4700). The observed micro morphology is shown in Figure 4.

As can be seen from Figure 4, the surface of raw CL-20 is relatively rough and has obvious sharp edges and corners, uneven size, irregular diamond shape, and particle size of $20 \mu \mathrm{m} \sim 100 \mu \mathrm{m}$. The refined CL-20 particles prepared by the pressure ultrasonic spray refining device were smaller, sharp edges and corners disappeared, the particles were oval, the surface was smooth, and the agglomeration between particles was serious. The particle size was about $1 \mu \mathrm{m} \sim 2 \mu \mathrm{m}$. However, the siphon ultrasonic spray refining device was made to refine CL-20; the shape of the particles was spherical, round, and dense; the dispersion between particles was good; the agglomeration between particles was significantly reduced; and the particle size was about $800 \mathrm{~nm} \sim 1 \mu \mathrm{m}$.

In conclusion, compared with the raw CL-20, the particle size of pressure- and siphon-refined CL-20 is significantly smaller, and the siphon-refined CL-20 is more round and dense than the pressure-refined CL-20. Therefore, it is the most suitable process to refine CL-20 by siphon ultrasonicassisted spray refining.

3.2. XRD Analysis. The XRD patterns of raw CL-20, pressurerefined CL-20, and siphon-refined CL-20 particles are shown in Figure 5.

According to Figure 5, the pressure-refined CL-20 has obvious characteristic diffraction peaks at $12.56^{\circ}, 13.82^{\circ}$, $25.76^{\circ}$, and $30.29^{\circ}$, and the siphon-refined CL-20 has obvious characteristic diffraction peaks at $12.53^{\circ}, 13.79^{\circ}, 25.76^{\circ}$, and $30.32^{\circ}$. By comparing the XRD diffraction patterns of the three samples with those of the standard card (00-050-2045), the positions of the two kinds of refined
CL-20 diffraction angles are basically the same as that of the raw CL-20 diffraction peak; we can see that the crystal forms of the three samples are $\varepsilon$ type.

3.3. DSC Thermal Decomposition Performance Analysis. Differential scanning calorimetry (DSC-131) was used to test the thermal decomposition performance of pressurerefined CL-20, siphon-refined CL-20, and raw CL-20. Figure 6 shows the DSC curve at the heating rate of $5^{\circ} \mathrm{C} / \mathrm{min}, 10^{\circ} \mathrm{C} / \mathrm{min}$, and $20^{\circ} \mathrm{C} / \mathrm{min}$.

It can be seen from Figure 6 that after heating, the raw CL-20 first passes through a period of thermal decomposition delay, and then, the decomposition speed is gradually accelerated at $228.70^{\circ} \mathrm{C}, 233.90^{\circ} \mathrm{C}$, and $251.27^{\circ} \mathrm{C}$, reaching the maximum value of decomposition speed at $242.15^{\circ} \mathrm{C}$, $250.51^{\circ} \mathrm{C}$, and $258.37^{\circ} \mathrm{C}$, and then, the decomposition speed drops rapidly until the end of decomposition. The reason for this phenomenon is that when the explosive molecules decompose, they do not immediately form the final decomposition products. When the temperature is low, the number of active molecules is small and the explosive molecules are in a relatively stable state. However, with the increase of temperature, the number of active molecules increases gradually, and the decomposition speed also increases until the decomposition stops. At the same time, it can be seen that the thermal decomposition trend of pressure-refined CL-20 and siphon-refined CL-20 samples is consistent with that of raw CL-20, and the decomposition peak temperature increases with the increase of the heating rate. At the same heating rate, the decomposition peak temperature of the two kinds of refined CL-20 was earlier than that of the raw CL-20, and the peak temperature of the 


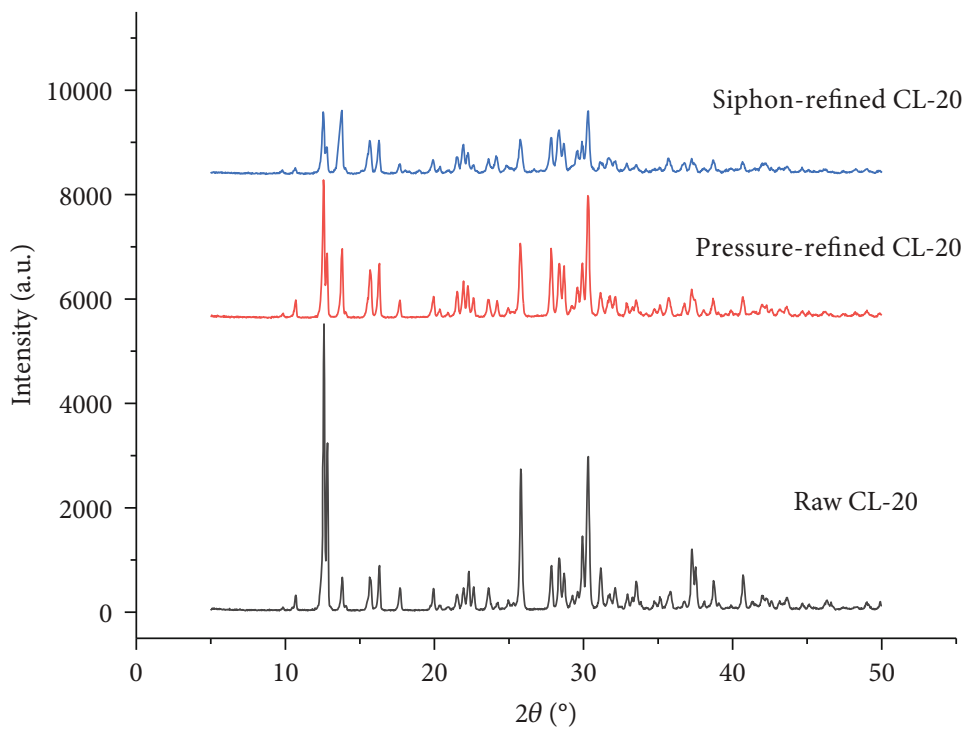

Figure 5: X-ray diffraction patterns of different CL-20 samples.

pressure-refined $\mathrm{CL}-20$ was $2.04^{\circ} \mathrm{C}, 2.37^{\circ} \mathrm{C}$, and $2^{\circ} \mathrm{C}$ earlier than that of the siphon-refined CL-20. This shows that the siphon-refined CL-20 particles are easier to decompose than the raw CL-20 and the pressure-refined CL-20. This is due to the decrease of CL-20 particle size, the increase of specific surface area, and the increase of activity of explosive particles, which makes the maximum decomposition peak temperature lower.

According to the data shown in Figure 6, the decomposition peak temperature at different heating rates is used. The apparent activation energies of the three samples are calculated by Kissinger [19] (formula (1)), Ozawa [20] (formula (2)), and Starink [21] (formula (3)), and the average values are taken to obtain the average apparent activation energies and preexponential factor $A$ of each sample. The results are shown in Table 1. The Kissinger fitting lines of raw CL-20, pressure-refined CL-20, and siphon-refined CL-20 are shown in Figure 7. It can be seen from Figure 7 that $R$-square is about $99 \%$, indicating that the measurement data is accurate and reliable:

$$
\begin{aligned}
\ln \left(\frac{\beta_{i}}{T_{\mathrm{p} i}^{2}}\right) & =\ln \left(\frac{A R}{E_{\mathrm{a}}}\right)-\frac{E_{\mathrm{a}}}{R T_{\mathrm{p} i}}, \\
\lg \beta & =\lg \left(\frac{A E}{R G(\alpha)}\right)-2.315-0.4567 \frac{E}{R T}, \\
\ln \left(\frac{\beta_{i}}{T_{\mathrm{p} i}^{1.8}}\right) & =C_{s}-1.0037 \frac{E_{\mathrm{a}}}{R T_{\mathrm{p} i}}, \\
T_{\mathrm{p} i} & =T_{\mathrm{p} 0}+b \beta_{i}+c \beta_{i}^{2}, \\
T_{b} & =\frac{E_{\mathrm{a}}-\sqrt{E_{\mathrm{a}}^{2}-4 R E_{\mathrm{a}} T_{\mathrm{p} 0}}}{2 R} .
\end{aligned}
$$

In the formula, $T_{\mathrm{p}}$ is the peak temperature of explosive decomposition temperature $(\mathrm{K})$ at the heating rate $\beta, R$ is the gas constant $\left(8.314 \mathrm{~J} \cdot \mathrm{mol}^{-1} \cdot \mathrm{K}^{-1}\right), \beta$ is the heating rate $\left(\mathrm{K} \cdot \mathrm{min}^{-1}\right.$ or $\left.\mathrm{s}^{-1}\right), A$ is the preexponential factor $\left(\mathrm{min}^{-1}\right.$ or s$\left.{ }^{-1}\right)$, and $E_{\mathrm{a}}$ is the apparent activation energy $\left(\mathrm{kJ} \cdot \mathrm{mol}^{-1}\right)$. The decomposition peak temperature $T_{\mathrm{p} 0}$ can be obtained when the heating rate $\beta$ tends to 0 by using the obtained apparent activation energy $E_{\mathrm{a}}$ and formula (4). The critical temperature $T_{b}$ of thermal explosion can be calculated by formula (5) [22]. Table 1 shows the calculation results.

It can be seen from Table 1 that the apparent activation energy of pressure-refined CL-20 and siphon-refined CL-20 samples is $13.3 \mathrm{~kJ} / \mathrm{mol}$ and $11.95 \mathrm{~kJ} / \mathrm{mol}$ higher than that of raw CL-20, respectively. The results show that the refined CL-20 needs higher energy to be activated during decomposition, and the thermal stability of the refined CL-20 is higher than that of the raw CL-20. The critical temperature of thermal explosion of pressure-refined CL-20 and siphonrefined CL-20 is $2.2^{\circ} \mathrm{C}$ and $3.55^{\circ} \mathrm{C}$ lower than that of raw CL-20, respectively, which shows that the thermal sensitivity of the refined CL-20 is improved, and the thermal sensitivity of siphon-refined CL-20 is higher than that of pressurerefined CL-20.

According to the above calculated data, the Gibbs free energy $\left(\Delta G^{\#}\right)$, activation entropy $\left(\Delta S^{\#}\right)$, and activation enthalpy $\left(\Delta H^{\#}\right)$ of each sample can be calculated by using formulas (6), (7), and (8) [23]. The results are shown in Table 2:

$$
\begin{gathered}
\Delta H^{\#}=E_{\mathrm{a}}-R T_{\mathrm{p}}, \\
A \exp \frac{-E_{\mathrm{a}}}{R T_{\mathrm{p}}}=\frac{K_{B} T_{\mathrm{p}}}{h} \exp \frac{-\Delta G^{\#}}{R T_{\mathrm{p}}}, \\
\Delta G^{\#}=\Delta H^{\#}-T_{\mathrm{p}} \Delta S^{\#} .
\end{gathered}
$$




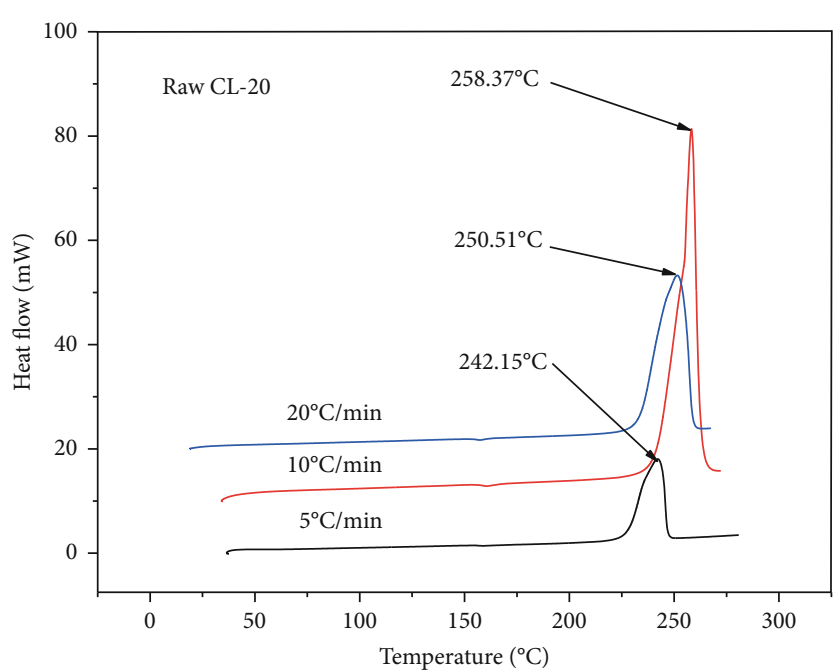

(a)

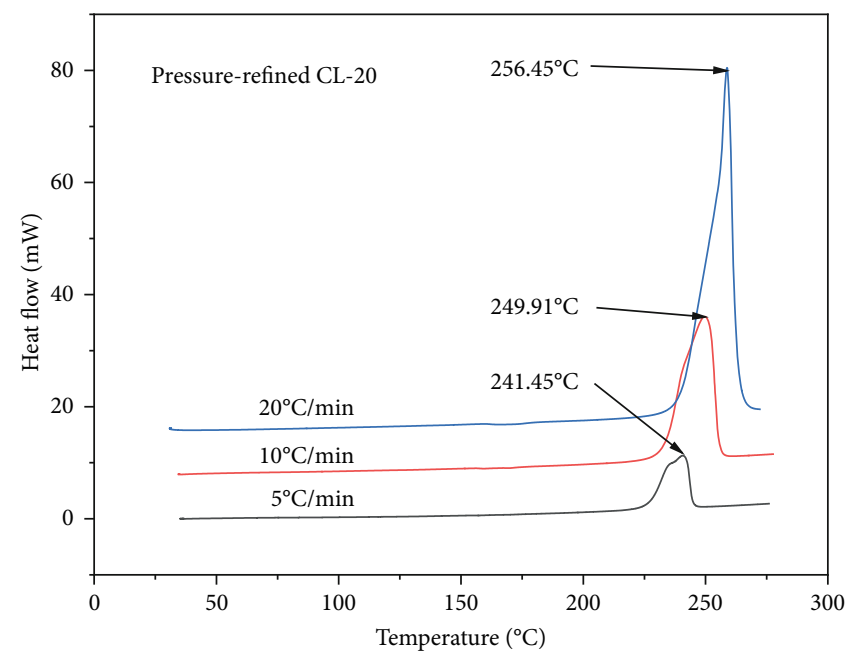

(b)

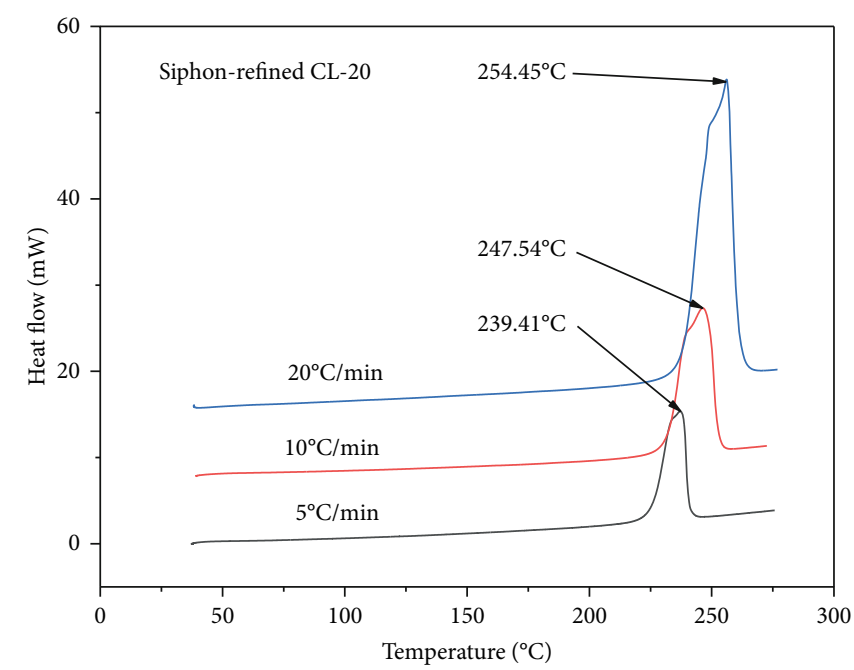

(c)

Figure 6: DSC curves of raw CL-20, pressure-refined CL-20, and siphon-refined CL-20.

TABLE 1: Activation energy and critical temperature of thermal explosion for different samples.

\begin{tabular}{|c|c|c|c|c|c|c|c|}
\hline \multirow{2}{*}{ Sample } & \multicolumn{3}{|c|}{$E_{\mathrm{a}}\left(\mathrm{kJ} \cdot \mathrm{mol}^{-1}\right)$} & \multirow{2}{*}{$\bar{E}_{\mathrm{a}}\left(\mathrm{kJ} \cdot \mathrm{mol}^{-1}\right)$} & \multirow{2}{*}{$\lg \left(\mathrm{A} / \mathrm{S}^{-1}\right)$} & \multirow{2}{*}{$T_{\mathrm{p} 0}(\mathrm{~K})$} & \multirow{2}{*}{$T_{b}\left({ }^{\circ} \mathrm{C}\right)$} \\
\hline & Kissinger & Ozawa & Starink & & & & \\
\hline Raw CL-20 & 185.78 & 184.94 & 185.97 & 185.56 & 18.45 & 503.99 & 515.89 \\
\hline Pressure-refined CL-20 & 199.33 & 197.80 & 199.46 & 198.86 & 19.87 & 502.68 & 513.69 \\
\hline Siphon-refined CL-20 & 197.96 & 196.47 & 198.09 & 197.51 & 19.82 & 501.31 & 512.34 \\
\hline
\end{tabular}

In the formula, $K_{B}$ and $h$ are the Boltzmann constant and the Planck constant, respectively, $K_{B}=1.381 \times 10^{-23} \mathrm{~J} \cdot \mathrm{K}^{-1}$, $h=6.626 \times 10^{-34} \mathrm{~J} \cdot \mathrm{s}^{-1} ; T_{\mathrm{p}}$ is the decomposition peak temperature when the heating rate approaches 0 .

It can be seen from Table 2 that $\Delta G^{\#}$ of all samples is greater than 0 , which means that all samples cannot be spontaneous in the process of thermal decomposition. Under normal storage conditions, the sample will be in a stable state. The pressure-refined CL-20 has the highest $\Delta G^{\#}$, indicating that the decomposition products are the most in the reaction process. $\Delta H^{\#}$ of pressure-refined CL-20 and siphonrefined CL-20 are $13.32 \mathrm{~kJ} / \mathrm{mol}$ and $11.97 \mathrm{~kJ} / \mathrm{mol}$ higher than that of raw CL-20, respectively, which shows that the refined CL-20 needs more energy from the outside to produce chemical reaction.

3.4. The Impact Sensitivity. The impact sensitivity of raw CL-20, pressure-refined CL-20, and siphon-refined CL-20 


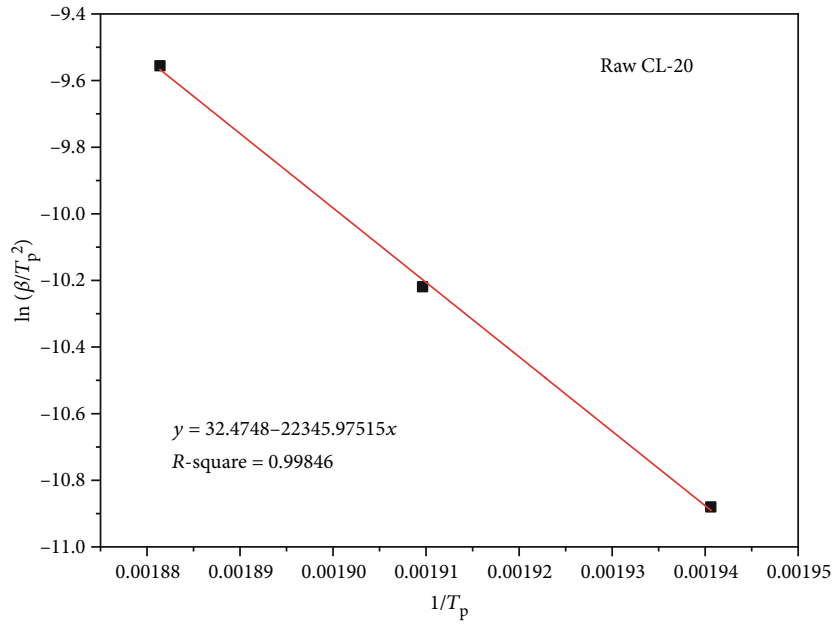

(a)

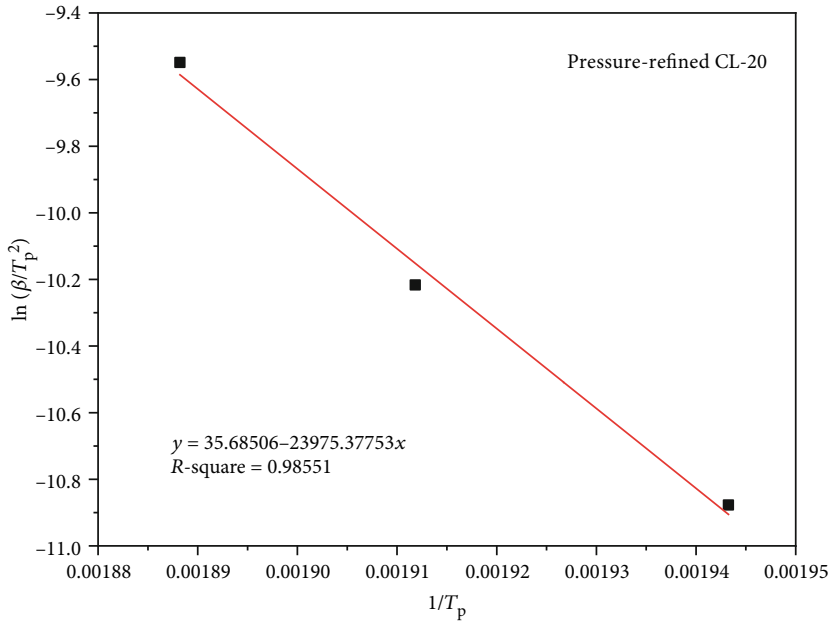

(b)

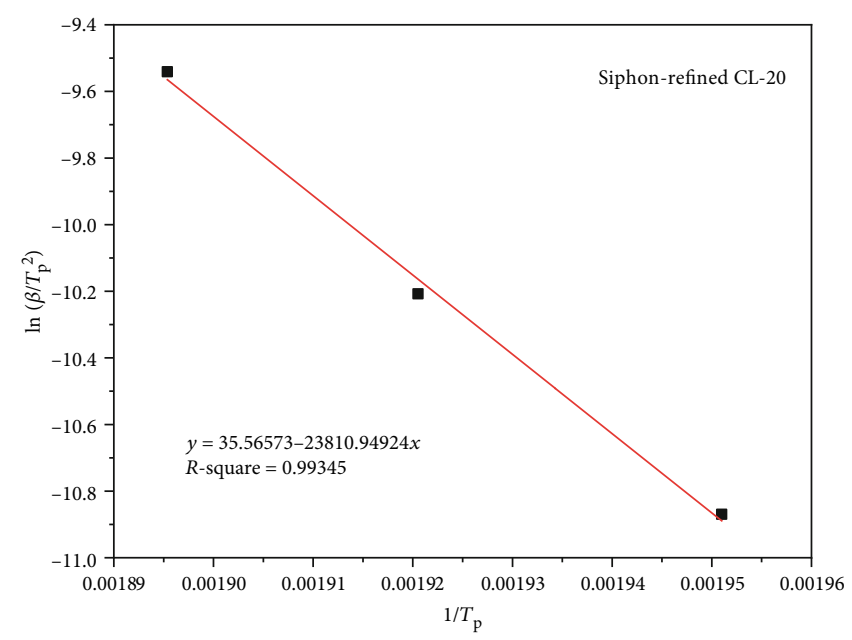

(c)

FIgURE 7: The Kissinger fitting lines of raw CL-20, pressure-refined CL-20, and siphon-refined CL-20.

TABLE 2: Thermodynamic parameters for different samples.

\begin{tabular}{lccc}
\hline Sample & $\Delta G\left(\mathrm{~kJ} \cdot \mathrm{mol}^{-1}\right)$ & $\Delta H\left(\mathrm{~kJ} \cdot \mathrm{mol}^{-1}\right)$ & $\Delta S\left(\mathrm{~J} \cdot \mathrm{mol}^{-1} \cdot \mathrm{K}^{-1}\right)$ \\
\hline Raw CL-20 & 133.16 & 181.37 & 95.66 \\
Pressure-refined CL-20 & 132.88 & 194.69 & 122.96 \\
Siphon-refined CL-20 & 132.22 & 193.34 & 121.93 \\
\hline
\end{tabular}

was tested by a self-made impact sensitivity tester. The test results are shown in Table 3.

As can be seen in Table 3, the characteristic drop height $H_{50}$ of raw CL-20 is $17.9 \mathrm{~cm}$. The impact sensitivity of pressure-refined CL-20 is $12.6 \mathrm{~cm}$ higher than that of raw CL-20, and the impact sensitivity of siphon-refined CL-20 is $14.8 \mathrm{~cm}$ higher than that of raw CL-20. The results show that the impact sensitivity of the particles obtained by using two kinds of ultrasonic-assisted spray device is significantly reduced, while the impact sensitivity of siphon-refined CL-20 is lower than that of pressure-refined CL-20.
TABLE 3: Impact sensitivity of raw CL-20, pressure-refined CL-20, and siphon-refined CL-20.

\begin{tabular}{lcc}
\hline Sample & $H_{50}(\mathrm{~cm})$ & Standard deviation \\
\hline Raw CL-20 & 17.9 & 0.047 \\
Pressure-refined CL-20 & 30.5 & 0.034 \\
Siphon-refined CL-20 & 32.7 & 0.043 \\
\hline
\end{tabular}

The reasons are as follows: raw CL-20 particles have a rough surface, sharp edges, and uneven size. Under the condition of impact, particles rub with each other, which is easy 
to form "explosion hot spot." However, after recrystallization and refinement, the surface of the particles is smooth, the particle size is reduced, and the particles are uniformly dispersed. Therefore, as the particle size becomes smaller, the particle surface area increases, and the probability of "explosion hot spot" between particles decreases, so that the impact sensitivity will be reduced.

\section{Conclusion}

In this paper, the submicron CL-20 was prepared by using two kinds of refining experimental devices. Compared with the raw CL-20, the particles of pressure-refined CL-20 and siphon-refined CL-20 are obviously smaller. At the same time, the particle size of siphon-refined CL-20 is $800 \mathrm{~nm} \sim 1 \mu \mathrm{m}$, which is more smooth, mellow, and dense than that of pressure-refined CL-20. The peak diffraction angle of pressure and siphon-refined CL-20 is basically the same as that of raw CL-20, and the crystal forms of the three samples are $\varepsilon$ type. At the same time, the peak strength of pressure-refined CL-20 and siphon-refined CL-20 decreased obviously. The thermal stability of pressure-refined CL-20 and siphon-refined CL-20 is higher than that of raw CL-20, so more energy needs to be absorbed from the outside to produce chemical reaction. The thermal sensitivity of the refined CL-20 particles is improved. The thermal sensitivity of the siphon-refined CL-20 is higher than that of the pressure-refined CL-20. The impact sensitivity of siphon-refined CL-20 is lower than that of pressure-refined CL-20.

\section{Data Availability}

The data used to support the finding of this study are available from the corresponding authors upon request.

\section{Conflicts of Interest}

The authors declare that they have no conflicts of interest.

\section{References}

[1] Y. Xu, Q.-J. Jiao, Q.-Z. Cui, W.-Z. Xu, and X.-X. Zhang, "Preparationof ultrafine and spherical $\varepsilon$-CL-20 by spray and ultrasound-assisted method," Chinese Journal of Energetic Materials, vol. 24, no. 11, pp. 1075-1079, 2016.

[2] X. Song, Y. Wang, and C. An, "Thermochemical properties of nanometer CL-20 and PETN fabricated using a mechanical milling method," AIP Advances, vol. 8, no. 6, 2018.

[3] H. Qiu, R. B. Patel, R. S. Damavarapu, and V. Stepanov, "Nanoscale 2CL-20·HMX high explosive cocrystal synthesized by bead milling," CrystEngComm, vol. 17, no. 22, pp. 40804083, 2015.

[4] X. Guo, G. Ouyang, J. Liu et al., "Massive preparation of reduced-sensitivity nano CL-20 and its characterization," Journal of Energetic Materials, vol. 33, no. 1, pp. 24-33, 2015.

[5] N. Degirmenbasi, Z. Peralta-Inga, U. Olgun, H. Gocmez, and D. M. Kalyon, "Recrystallization of CL-20 and HNFX from solution for rigorous control of the polymorph type: part II, experimental studies," Journal of Energetic Materials, vol. 24, no. 2, pp. 103-139, 2006.

[6] Z. W. Song, Q. L. Yan, X. J. Li, X. F. Qi, and M. Liu, "Crystal transition of $\varepsilon$-CL-20 in different solvents," Chinese Journal of Energetic Materials, vol. 6, pp. 648-653, 2010.

[7] J. Wang, J. Li, C. An, C. Hou, W. Xu, and X. Li, "Study on ultrasound-and spray-assisted precipitation of CL-20," Propellants, Explosives, Pyrotechnics, vol. 37, no. 6, pp. 670-675, 2012.

[8] B. Y. Ye, C. W. An, J. Y. Wang, and X. H. Geng, "Formation and properties of HMX-based microspheres via spray drying," RSC Advances, vol. 7, no. 56, pp. 35411-35416, 2017.

[9] H. Aijun and Q. Taiqiu, "Crystallization technique with supercritical fluids and its application research," Chemical Industry and Engineering Progress, vol. 21, no. 2, pp. 127-130, 2002.

[10] K. Zhu, G. Li, and Y. Luo, "Preparation of ultrafine CL-20 by supercritical CO2 anti-solvent method," Chinese Journal of Energetic Materials (Hanneng Cailiao), vol. 20, no. 4, pp. 445-449, 2012.

[11] F. F. Shang and J. L. Zhang, "Effect of solvent on particle morphology and crystal phase in recrystallization of HMX by different supercritical carbon dioxide as antisolvent," Initiators \& Pyrotechnics, vol. 1, pp. 16-20, 2014.

[12] Y. Wang, X. Song, D. Song, W. Jiang, H. Liu, and F. Li, “A versatile methodology using sol-gel, supercritical extraction, and etching to fabricate a nitramine explosive: nanometer HNIW," Journal of Energetic Materials, vol. 31, no. 1, pp. 49-59, 2013.

[13] Y. Bayat and V. Zeynali, "Preparation and characterization of nano-CL-20 explosive," Journal of Energetic Materials, vol. 29, no. 4, pp. 281-291, 2011.

[14] Y. Bayat, M. Zarandi, M. A. Zarei, R. Soleyman, and V. Zeynali, "A novel approach for preparation of CL-20 nanoparticles by microemulsion method," Journal of Molecular Liquids, vol. 193, pp. 83-86, 2014.

[15] P. Zhang, X.-Y. Guo, J.-Y. Zhang, Z.-H. Wang, and S.-W. Li, "Preparation of spherical ultrafine CL-20 by mechanical grinding," Chinese Journal of Energetic Materials, vol. 21, no. 6, pp. 738-742, 2013.

[16] X. Jia and J. Wang, "Preparation and characterization of spherical submicron $\varepsilon$-CL-20 via green mechanical demulsification," Journal of Energetic Materials, vol. 37, no. 4, pp. 475-483, 2019.

[17] X. Jia, L. Wei, X. Liu et al., "Fabrication and characterization of submicron scale spherical RDX, HMX, and CL-20 without soft agglomeration," Journal of Nanomaterials, vol. 2019, Article ID 7394762, 8 pages, 2019.

[18] Z.-Y. Pang, W.-Z. Xu, Y.-R. Zhang, C. Ping, and J.-Y. Wang, "Preparation of ultrafine and spherical CL-20 by pressure type of spraying," Initiators \& Pyrotechnics, vol. 2, pp. 52-55, 2018.

[19] H. E. Kissinger, "Reaction kinetics in differential thermal analysis," Analytical Chemistry, vol. 29, no. 11, pp. 1702-1706, 1957.

[20] T. Ozawa, "A new method of analyzing thermogravimetric data," Bulletin of the Chemical Society of Japan, vol. 38, no. 11, pp. 1881-1886, 1965.

[21] M. J. Starink, “Analysis of hydrogen desorption from linear heating experiments: accuracy of activation energy determinations," International Journal of Hydrogen Energy, vol. 43, no. 13, pp. 6632-6641, 2018. 
[22] Z. Tonglai, H. Rongzu, X. Yi, and L. Fuping, "The estimation of critical temperatures of thermal explosion for energetic materials using non-isothermal DSC," Thermochimica Acta, vol. 244, pp. 171-176, 1994.

[23] B. Ye, C. An, Y. Zhang, C. Song, X. Geng, and J. Wang, "Onestep ball milling preparation of nanoscale CL-20/graphene oxide for significantly reduced particle size and sensitivity," Nanoscale Research Letters, vol. 13, no. 1, p. 42, 2018. 